\title{
Uma vida dedicada ao Real Serviço \\ João Pereira Caldas, dos sertões do Rio Negro à nomeação para o Conselho Ultramarino (1753-1790)*
}

\author{
A life dedicated to Royal Service \\ João Pereira Caldas, from the hinterlands of Rio Negro \\ to the nomination for the Overseas Council (1752-1790)
}

FABIANO VILACAA DOS SANTOS

Doutor em História Social - USP

Professor Substituto da UERJ

Pesquisador da Revista de História da Biblioteca Nacional Avenida Churchill, 109, sala 1101, Centro, Rio de Janeiro, RJ, 20020-050.

fabianovilaca@gmail.com

RESUMO Este artigo analisa a trajetória no Real Serviço de João Pereira Caldas, conhecido na historiografia como o governador responsável pela organização administrativa do Piauí. Antes, porém, de considerar a atuação do jovem militar minhoto, o artigo apresenta seus traços biográficos, relações familiares e conexões na Corte - aspectos essenciais na análise do recrutamento dos administradores coloniais. Em seguida, são abordados os deslocamentos de Pereira Caldas, que foi ainda governador e capitãogeneral do Estado do Grão-Pará e Maranhão e comissário do Tratado de Santo Ildefonso. Encerrou sua carreira no Conselho Ultramarino. Mas, na prática, a nomeação representou apenas mais uma distinção, não tendo resultado em participação efetiva nas decisões do Conselho. À luz do mecanismo de serviço e remuneração, tais percursos são apreciados levando-se

Artigo recebido em: 15/04/2010. Aprovado em: 29/06/2010. 
em conta fatores como a experiência adquirida por Pereira Caldas, a repercussão de seus préstimos em Lisboa e as relações políticas e pessoais que o mantiveram atuante nas conquistas do Norte.

Palavras-chave João Pereira Caldas, trajetória, Real Serviço, Conselho Ultramarino

ABSTRACT This article examines João Pereira Caldas's career within the Royal Service. Pereira Caldas is historically known as the governor of the Piaui captaincy. However, before considering the portrayal of the young military, this article presents his biographical traits, his family relationships and connections in the Court - key issues to analyze the recruitment of colonial administrators. Then, we will look at the various shifts in Pereira Caldas career, from governor and captain-general of the Grão Pará and Maranhão captainces to commissioner of the Treaty of San Ildefonso. His career came to an end in the Overseas Council. But, actually, the nomination only represented a distinction, and didn't result in effective participation in the decisions of the Council. In light of the mechanism of service and remuneration, those different paths are assessed taking into account factors such as the experience gained by Pereira Caldas, the impact of his services in Lisbon and his political and personal relationships which maintained him active in all the achievements in the North.

Keywords João Pereira Caldas, career, Royal Service, Overseas Council

\section{Introdução}

No âmbito das conquistas ultramarinas e, especialmente, no conjunto dos governantes que nelas atuaram, este artigo privilegia o Estado do Grão-Pará e Maranhão, uma unidade administrativa criada no período pombalino ainda pouco explorada do ponto de vista do recrutamento, das experiências e das remunerações dos préstimos dos seus governadores. Como João Pereira Caldas, cuja trajetória foi particularizada neste trabalho. Apontado por Joaquim Romero Magalhães como um dos "governadores pombalinos" - pela adesão aos projetos gestados durante o ministério de Sebastião José de Carvalho e Melo -, em seus percursos pela Amazônia portuguesa, o militar minhoto construiu uma sólida carreira, que se manteve em ascensão apesar das mudanças no cenário político da Corte.

1 MAGALHÃES, Joaquim Romero. Sebastião José de Carvalho e Melo e a economia do Brasil. Lisboa: ICS, 2005. Disponível em: www.ics.ul.pt/agenda/seminarioshistoria/seminarios historia2004 2005.htm; MONTEIRO, Nuno Gonçalo. O governo da monarquia e do Império: o provimento de ofícios principaiš durante o período pombalino. In: SOUZA, Laura de Mello; FURTADO, Júnia Ferreira; BICALHO, Maria Fernanda. (orgs.) O governo dos povos. São Paulo: Alameda, 2009, p.508-510. 


\section{Do Alto Minho aos sertões do Rio Negro}

Nascido na Quinta de Sende, em Monção, vila minhota na fronteira com a Galiza, no dia 4 de agosto de 1736, João Pereira Caldas foi o mais jovem governador do Estado do Grão-Pará e Maranhão, subordinado a Lisboa, criado em 1751 e extinto em 1772-1774. De família distinta, representante de um estrato da nobreza que Nuno Gonçalo Monteiro denomina "fidalguia de província"2, tornou-se moço fidalgo da Casa Real antes de completar oito anos de idade. ${ }^{3}$ Filho do brigadeiro Gonçalo Pereira Lobato e Sousa e de D. Joana Maria Pereira de Castro - ambos provenientes de famílias enraizadas em Monção e Viana do Castelo -, chegou a Belém na companhia deste e de um irmão mais novo, Gonçalo José Pereira de Castro e Caldas, para secundar os trabalhos de demarcação de limites previstos no Tratado de Madri (1750).

Na historiografia, aparece como um dos mais ativos agentes da colonização nas conquistas do Norte, tendo se destacado não só na estruturação da capitania do Piauí, mas também na execução de um arrojado plano de recuperação econômica do Estado na década de 1770 e, posteriormente, nas demarcações do Tratado de Santo IIdefonso. ${ }^{4}$ Contudo, pesam sobre João Pereira Caldas certas distorções biográficas: o equivocado uso do "dom" antes de seu nome - situando-o erroneamente no seio da alta nobreza lusitana -, o natalício que lhe acrescentaria 16 anos (nasceu em 1736 e não em 1720) e o princípio da carreira militar. ${ }^{5}$

Os enganos relativos à biografia de Pereira Caldas podem ser corrigidos a partir da análise de seu processo de habilitação à Ordem de Cristo. A mercê foi estendida ao seu irmão Gonçalo José na mesma ocasião, ou seja, pouco antes da partida para Belém. João Pereira Caldas, que iniciara a carreira das armas em 1749, aos 13 anos, não havia completado 17 quando recebeu a mercê do hábito e seguia com a patente de capitão de Infantaria. ${ }^{6}$ Dada a pressa do embarque na frota que partia para o Grão-Pará e, conforme os estatutos da Ordem de Cristo, Pereira Caldas e o irmão receberam de D. José I a dispensa das provanças e da menoridade. ${ }^{7}$ Apesar da mercê, a

2 MONTEIRO, Nuno Gonçalo. Elites e poder: entre o Antigo Regime e o Liberalismo. Lisboa: Imprensa de Ciências Sociais; Instituto de Ciências Sociais da Universidade de Lisboa, 2003, p.75-77.

3 Lisboa. Instituto dos Arquivos Nacionais - Torre do Tombo (IANTT). Registro Geral de Mercês. D. João V, livro 34 fls.470v-471.

4 Cf. NUNES, Odilon. Pesquisas para a história do Piauí. $2^{a}$.ed. Rio de Janeiro: Artenova, 1975, v.1, p.127. RAMINELLI, Ronald. João Pereira Caldas. In: VAINFAS, Ronaldo. (org.) Dicionário do Brasil colonial (1500-1822). Rio de Janeiro: Objetiva, 2000.

5 Cf. GONÇALVES, Wilson Carvalho. Os homens que governaram o Piauí. Teresina: Gráfica Júnior, 1989, p.15. Ver também ALMEIDA, Cândido Mendes de. (org.) Código philippino ou ordenações e leis do reino de Portugal: recopiladas por mandado d'El Rei D. Philippe I. 14ª ed., Rio de Janeiro: s/n, 1870, p.1336.

6 IANTT. Habilitações da Ordem de Cristo. Letra J, maço 4, doc. n.2.

7 Cf. OLIVAL, Fernanda. As ordens militares e o Estado Moderno: honra, mercê e venalidade em Portugal (16411789). Lisboa: Estar Editora, 2001, p.206-214 e 456 
carta régia para o lançamento do hábito de Cristo só foi expedida quando o militar se preparava para encerrar a carreira no ultramar. ${ }^{8}$

A carreira de João Pereira Caldas no Real Serviço ganhou impulso pouco depois da chegada a Belém, em 1753. No mesmo ano, foi indicado, juntamente com João Batista de Oliveira, também capitão de Infantaria, para ajudante de sala (ou ajudante de ordens) do governador e capitão-general Francisco Xavier de Mendonça Furtado. Pereira Caldas, "pela qualidade de sua pessoa como por ser filho do brigadeiro Gonçalo Pereira Lobato e Sousa", recém-nomeado governador do Maranhão, e João Batista de Oliveira, por ter servido 16 anos na Armada com "préstimo e atividade" presenciados pelo próprio Mendonça Furtado. ${ }^{9}$ Foi, portanto, na qualidade de ajudante de ordens do capitão-general e 1ํ comissário de limites da repartição Norte, que o jovem militar minhoto deixou Belém, em 2 de outubro de 1754, na expedição que se dirigiu ao Rio Negro para a demarcação do Tratado de Madri.

No mesmo ano, João Pereira Caldas recebeu a comenda de São Mamede de Troviscoso, da Ordem de Cristo, por não ter podido se encartar na alcaidaria-mor do Castelo da Piconha, mercê concedida a outrem. Três anos depois, graças às instâncias do pai, teve confirmada a patente de sargento-mor de Infantaria. ${ }^{10}$ Mas o principal passo da trajetória de Pereira Caldas ainda estava por ser dado, após mais uma demonstração da proteção de Mendonça Furtado e das boas relações entre este e a família do sargento-mor.

Em uma carta enviada ao governador do Maranhão, datada de 13 de outubro de 1757, Mendonça Furtado dispensou o brigadeiro Gonçalo Pereira dos agradecimentos pelas honras concedidas ao seu filho, nos seguintes termos: "Ihe rendi justiça e o seu procedimento é tão notório que não há uma única pessoa a quem deixe de edificar, e V.S. ${ }^{a}$ tem que dar infinitas graças a Deus, de lhe dar semelhante filho". Insinuou, inclusive, a intenção de distingui-lo pelos bons serviços: "brevemente darei a V.S. ${ }^{a}$ uma demonstração de que assim o entendo e lhe hei de certamente render justiça". ${ }^{11}$ Afinal, João Pereira Caldas e seu pai demonstraram efetivo interesse pelos projetos pombalinos para a Amazônia. Um dos sinais dessa adesão foi a aquisição

8 IANTT. Chancelaria da Ordem de Cristo. Livro 264, fls.405-405v e livro 270, fl.159; Registro Geral de Mercês. D. Maria I, livro 24, fl.236.

9 Correspondência dos governadores do Pará com a metrópole. Anais da Biblioteca e Arquivo Público do Pará. $2^{\mathrm{a}}$.ed. Belém, t.2, p.55, 1968.

10 IANTT. Registro Geral de Mercês. D. José I, livro 6, fls.377v-378v; Chancelaria da Ordem de Cristo. Livro 264, fl.431v; Ministério do Reino. Decretos (1745-1800). Pasta 4, n.107.

11 MENDONÇA, Marcos Carneiro de. (coord.) A Amazônia na era pombalina. Correspondência inédita do governador e capitão-general do Estado do Grão-Pará e Maranhão Francisco Xavier de Mendonça Furtado (1751-1759). São Paulo: Instituto Histórico e Geográfico Brasileiro, 1963, t. 3, p.1152-1153. 
de cotas - Pereira Caldas uma e Gonçalo Pereira duas - da Companhia Geral de Comércio do Grão-Pará e Maranhão, fundada em 1755. ${ }^{12}$

Diante do exposto, é possível admitir que a demonstração de "justiça" ao militar - a nomeação para governador do Piauí - tenha partido de uma indicação de Mendonça Furtado, pouco tempo antes de deixar o governo do Estado. Em ofício ao secretário Tomé Joaquim da Costa Corte Real, de 12 de fevereiro de 1759, Mendonça Furtado forneceu as melhores referências de seu ajudante de ordens:

tenho dele todo o bom conceito que pode ser, porque servindo de ajudante de sala deste governo há perto de seis anos, ainda não vi neste oficial ação que não fosse de quem não tem imaginação alguma que não seja de honra, e de cristandade; Deus Nosso Senhor queira conservá-lo no mesmo estado, para que sirva à Sua Majestade como deve, e como eu me persuado a que ele o há de fazer. ${ }^{13}$

A missão de Pereira Caldas, um jovem militar sem experiência na função governativa, consistia em acabar com os abusos, extorsões e fraudes contra o patrimônio da Coroa na capitania de São José do Piauí.

\section{Uma prova de fogo: a organização administrativa do Piauí}

"Aquela capitania, já disse a V.Ex. ${ }^{2}$, que era um patrimônio de bacharéis, e que eles assim o tem entendido, e que há de custar à Sua Majestade muito a desapossá-los". ${ }^{14} \mathrm{O}$ trecho de uma carta de Francisco Xavier de Mendonça Furtado a Sebastião José de Carvalho e Melo, seu irmão, expressa a situação em que se achava a administração do Piauí.

Os problemas da capitania decorriam - na visão do capitão-general da ação nefasta de alguns ouvidores e de padres da Companhia de Jesus. Muitas fazendas de gado do Piauí pertenciam ao Colégio dos Jesuítas da Bahia, herdadas de Domingos Afonso Mafrense - também conhecido por Domingos Afonso Sertão -, um dos desbravadores daquelas terras. ${ }^{15}$ Por volta de 1750, as desavenças quanto à demarcação das propriedades levaram o governo do Estado do Grão-Pará a tomar providências para apurar o envolvimento de oficiais régios.

"Para por em sossego e quietação aquela larga extensão de país" - acabando com os desmandos de oficiais régios e os descaminhos da Fazenda Real da Mocha, a principal vila do Piauí -, a Coroa nomeou o desembar-

12 Cf. DIAS, Manuel Nunes. Fomento e mercantilismo: a Companhia Geral do Grão-Pará e Maranhão (1755-1778). Belém: Universidade Federal do Pará, 1970, v.1, p.230-234.

13 Lisboa. Arquivo Histórico Ultramarino (AHU). Manuscritos Avulsos do Pará (MAPA). CD 5, cx.44, doc.4013.

14 MENDONÇA, Marcos Carneiro de. (coord.) A Amazônia na era pombalina, t.3, p.1086.

15 Cf. ALENCASTRE, José Martins Pereira d'. Memória cronológica, histórica e corográfica da província do Piauí. Revista do Instituto Histórico e Geográfico Brasileiro. Rio de Janeiro, t.20, p.5, 1857. 
gador João da Cruz Diniz Pinheiro, homem da confiança de Mendonça Furtado, para o cargo de intendente-geral das colônias, do comércio, da agricultura e das manufaturas do Estado do Grão-Pará e Maranhão, criado especificamente para esta repartição. Foi estabelecido que Diniz Pinheiro - responsável por extensa jurisdição que incluía as capitanias do Pará, do Maranhão e do Piauí - receberia vencimentos equivalentes aos de ouvidor e ficaria subordinado ao governador e capitão-general do Estado. ${ }^{16}$

A necessidade de atalhar as improbidades verificadas na administração do Piauí - àquela altura um território formado basicamente por fazendas - pode ser entendida como um dos fatores que impulsionaram a concretização de uma ordem régia havia muito existente. Datava de 1718 o alvará que determinava a separação do Piauí da jurisdição do Maranhão. A vila da Mocha (tomada muitas vezes como a própria capitania) fora criada em 30 de junho de 1712, embora só tenha sido instalada por ordem régia de 26 de dezembro de 1717, mesmo ano em que foi criada a comarca do Piauí. No plano político, ficou sob a jurisdição da Bahia até 1715; no espiritual, esteve subordinado à diocese de Pernambuco, sediada em Olinda, de 1679 a 1728, e deste ano em diante à do Maranhão. ${ }^{17}$

Integrada ao projeto de revitalização das conquistas do Norte no período pombalino, a organização administrativa do Piauí pode ser entendida como resultado do somatório de alguns fatores: a necessidade de dar cumprimento ao alvará de 1718 e as constantes queixas do governadorgeral do Estado contra os magistrados enviados à vila da Mocha. Pode-se acrescentar um terceiro fator: a expulsão dos jesuítas, em 1759, sucedida quando a Coroa já havia fornecido as diretrizes para o estabelecimento da capitania, acontecimento que levou à demarcação e à distribuição das fazendas da Companhia.

A morte de João da Cruz Diniz Pinheiro, antes mesmo de chegar à Mocha, quase comprometeu o plano de "redenção da capitania do Piaú e o sólido estabelecimento desta". O fato levou não só à indicação de um substituto, Francisco Marcelino de Gouveia, desembargador da Casa da Suplicação, como precipitou a nomeação do sargento-mor João Pereira Caldas para governador, o qual chegou à vila da Mocha em 17 de setembro de 1759 e tomou posse três dias depois. A carta régia de 29 de julho de 1758, feita exatamente uma semana antes da que nomeou Francisco Marcelino, esclarecia que o desembargador deveria passar diretamente ao Piauí, onde trabalharia "de comum acordo" com Pereira Caldas e, prin-

16 Belém. Arquivo Público do Estado do Pará (APEPA). Códice 86, fls.20-20v

17 Cf. COSTA, F. A. Pereira da. Cronologia histórica do estado do Piauí, desde os seus tempos primitivos até a proclamação da República. $2^{a}$.ed. Rio de Janeiro: Artenova, 1974, p.77-86. 
cipalmente, estabelecia os princípios fundamentais para a montagem da máquina administrativa. ${ }^{18}$

As diretrizes a serem seguidas pelo governador podem ser resumidas em quatro aspectos essenciais: estabelecimento do governo político, com todo o aparato necessário ao exercício das funções públicas; cumprimento das leis de 6 e 7 de junho de 1755 a respeito da liberdade dos índios; organização do aparato militar; fundação de vilas para abrigar a população dispersa no interior, inclusive os índios, que deveriam ser mantidos afastados da tutela temporal dos religiosos, conforme o Diretório..$^{19}$

$\mathrm{O}$ aspecto mais detalhado na carta régia diz respeito à organização militar. João Pereira Caldas deveria montar um Regimento de Cavalaria auxiliar na vila da Mocha, formado por 10 companhias com 60 praças cada. As indicações para os postos de tenente-coronel, capitão, tenente, alferes e furriel deveriam ser submetidas à aprovação do governador e capitãogeneral do Estado, uma vez que o Piauí tornara-se independente no plano administrativo, mas continuava subordinado ao Grão-Pará no plano militar. O documento prescrevia claramente todos os detalhes da formação da tropa para a qual João Pereira Caldas, na qualidade de autoridade máxima da capitania, fora nomeado coronel. Mas, na prática, o governador enfrentou sérias dificuldades para satisfazer a um modelo de Regimento oriundo da metrópole, que absolutamente não dava conta da realidade de um lugar com população escassa e dispersa.

Passados quase três anos, de acordo com uma consulta submetida ao Conselho Ultramarino, em 21 de janeiro de 1761, Pereira Caldas ainda não havia criado o Regimento de Cavalaria auxiliar nos moldes da carta régia de 29 de julho de 1758, por não dispor a vila da Mocha de homens suficientes para formar as 10 companhias de 60 praças, ou seja, 600 soldados. A solução apontada pelo próprio governador em carta enviada em 1760 ao Conselho foi repartir as companhias pelas demais freguesias do Piauí. ${ }^{20}$

Quanto ao estabelecimento dos núcleos urbanos, a carta régia de 1758 estabelecia que após elaborar uma relação dos moradores de cada vila, João Pereira Caldas deveria convocá-los para conhecer o local mais adequado para a construção da praça principal, onde seria erguido o pelourinho, a igreja e demais edifícios públicos. Na mesma ocasião, o governador definiria o traço das novas habitações "fazendo delinear as casas dos

18 Rio de Janeiro. Fundação Biblioteca Nacional (FBN). Divisão de Manuscritos (DM). II-30, 36, 44 n.003.

19 Cf. ALMEIDA, Rita Heloísa de. Diretório dos Índios: um projeto de civilização no Brasil do século XVIII. Brasília: Ed. UnB, 1997; COELHO, Mauro Cezar. A cultura do trabalho: o Diretório dos Índios e um novo paradigma de colonização na Amazônia do século XVIII. In: QUEIROZ, Jonas Marçal de e COELHO, Mauro Cezar. (orgs.) Amazônia: modernização e conflito (séculos XVIII e XIX). Belém/Macapá: UFPA/NAEA/UNIFAP, 2001, p.57-79; SAMPAIO, Patrícia Melo. Administração colonial e legislação indigenista na Amazônia portuguesa. In: DEL PRIORE, Mary e GOMES, Flávio dos Santos. (orgs.) Os senhores dos rios: Amazônia, margens e histórias. Rio de Janeiro: Campus/ Elsevier, 2003, p.123-139.

20 IANTT. Ministério do Reino. Consultas do Conselho Ultramarino. Maço 314, cx.420. 
moradores por linha reta, de sorte que fiquem largas e direitas as ruas". ${ }^{21}$ A instrução estava de acordo com a concepção das povoações criadas no período pombalino, cujo objetivo era implantar e reforçar a autoridade régia e aproveitar o potencial produtivo - também entendido no aspecto humano - de territórios inexplorados, a exemplo do Piauí..$^{22}$

Não seria fácil, no entanto, estabelecer as vilas. A discrepância entre a legislação e a realidade local fez com que os primeiros tempos da administração de Pereira Caldas se transfigurassem em dificuldades, hesitações e incertezas quanto às possibilidades de cumprimento das ordens régias. Os principais obstáculos enfrentados pelo governador, um jovem militar de 23 anos, em sua prova de fogo, foram: a escassez de população, em grande parte internada nos sertões da capitania, formada basicamente por vaqueiros, índios, escravos africanos e mestiços; o fato de a população ser pouco afeita à vida urbana, permanecendo mais tempo nas fazendas de gado que compunham o território piauiense; os constantes ataques do gentio hostil que ameaçavam a paz dos moradores e a estabilidade das povoações.

Antes mesmo que uma nova carta régia, de 1761, chegasse ao conhecimento de Pereira Caldas, Francisco Xavier de Mendonça Furtado, então secretário de Estado da Marinha e Domínios Ultramarinos, enviou-lhe uma série de advertências que reiteravam os planos de fundação de vilas na capitania, deixando entrever - ao citar correspondências anteriores de Pereira Caldas - a hesitação que permeava as atitudes deste. Somente nos dias 18 e 19 de junho de 1761 - mesma data da carta régia que estabelecia a configuração das vilas no Piauí -, Mendonça Furtado endereçou pelo menos três cartas ao governador, dando-Ihe instruções para contornar as dificuldades encontradas.

Na carta de 18 de junho de 1761, o secretário aludiu a uma consulta de Pereira Caldas acerca dos ataques dos Acoroás, Timbiras e Gueguês às freguesias de Parnaguá e Gurguéia, no Piauí, e de Pastos Bons, no Maranhão. ${ }^{23}$ Na referida consulta, de 26 de janeiro de 1760, o governador relatara que os índios insultavam os comerciantes de passagem para as minas da Natividade e Goiás, que negociavam nas ditas freguesias, e os fazendeiros próximos à aldeias, matando-os, roubando suas casas e raptando suas mulheres e filhas. Para fazer frente ao gentio, pedia permissão à metrópole para declarar-lhes guerra, solicitando ao rei que ordenasse ao governador de Pernambuco o envio de tropas e de 500 ou 600 índios. Requeria o auxílio,

21 ALENCASTRE, José Martins Pereira d’. Memória cronológica, histórica e corográfica da província do Piauí, p.153.

22 Cf. DELSON, Roberta Marx. Povoações pombalinas. In: SILVA, Maria Beatriz Nizza da. (coord.) Dicionário da história da colonização portuguesa no Brasil. Lisboa: Editorial Verbo, 1994.

23 FBN. DM. 19, 4, 2, doc. 300, fl.172. 
pois não podia lançar mão dos moradores do Piauí sob o risco de deixar a capitania ainda mais despovoada e desprotegida. ${ }^{24}$

Mesmo apontando toda a sorte de problemas causados pelos ataques indígenas, principalmente no que se referia à estabilidade das povoações, João Pereira Caldas não obteve a permissão nem o apoio da metrópole para fazer guerra aos índios. Em lugar do conflito, deveria investir na pacificação, a fim de que "vendo o que se pratica com os outros que se aldearam, virão a reduzir-se, como tem sucedido nos sertões da Bahia com outras nações que pareciam igualmente ferozes". ${ }^{25}$

Contudo, no intervalo de apenas um dia houve uma mudança no discurso das autoridades metropolitanas. Se na carta de 18 de junho de 1761, mencionada acima, Pereira Caldas foi advertido a não guerrear com o gentio, no dia seguinte, na resposta a uma carta sua, de 15 de outubro de 1760, os termos eram outros. Dessa vez, Mendonça Furtado transmitiu ordens para que todos os moradores fossem convocados a contribuir com mantimentos para o sustento da tropa, embora nada dissesse sobre o efetivo a ser empregado. A guerra contaria ainda com o apoio do governo do Maranhão e deveria ser comunicada aos índios por meio de um bando no qual constaria que os cativos de guerra, exceto mulheres e crianças, seriam escravizados permanentemente. Os índios que, de antemão, concordassem em se sujeitar às leis vigentes seriam aldeados e tratados como livres.

Solucionada, em tese, a questão dos ataques indígenas como empeciIho à ocupação do território, resta analisar uma terceira carta de Mendonça Furtado, de 19 de junho de 1761, sobre as hesitações de Pereira Caldas no tocante à criação das vilas. Em carta de 25 de janeiro do ano anterior, o governador afirmara não ser possível erigir em vila mais que duas freguesias, a de Parnaguá e de Santo Antônio do Surubim, das oito existentes na capitania, dada a escassez e à dispersão da população. Para dar suporte à ação de Pereira Caldas, o secretário ditou-Ihe algumas instruções complementares: em primeiro lugar, deveria alardear aos quatro cantos a carta régia de 19 de junho de 1761, enfatizando o trecho inicial no qual a Coroa se dispunha a conceder privilégios aos que se interessassem pelo adiantamento da capitania. Mendonça Furtado referia-se aos benefícios e às mercês que poderiam ser obtidas pela população radicada em povoações bem ordenadas. ${ }^{26}$

Os demais meios para viabilizar a fundação das vilas incluíam a busca do apoio do clero, interessando-o no aumento da população e consequentemente dos dízimos; a escolha dos lugares mais adequados para as

24 IANTT. Ministério do Reino. Consultas do Conselho Ultramarino. Maço 314, cx.420.

25 FBN. DM. 19, 4, 2, doc. 300, fl.172.

26 Rio de Janeiro. Instituto Histórico e Geográfico Brasileiro (IHGB). Lata 358, doc.25. Ver também ALENCASTRE, José Martins Pereira d’. Memória cronológica, histórica e corográfica da província do Piauí, p.152. 
construções públicas por meio do voto dos principais de cada freguesia; e a atribuição aos moradores da responsabilidade pela construção da igreja, da câmara e da cadeia. Após a construção dos edifícios públicos, a fim de que Pereira Caldas não "desanim[asse] nas referidas fundações", Mendonça Furtado recomendava a instalação de seis ou sete famílias em cada freguesia, seguindo o exemplo da Bahia, onde as vilas "havendo principiado há poucos anos por seis ou sete casas se acham hoje populosas até o número de 500 e 600 vizinhos". ${ }^{27}$

Os procedimentos sugeridos na carta régia devem ter produzido o efeito desejado no ânimo do governador do Piauí. Em 13 de novembro de 1761, este comunicou à Câmara da Mocha a elevação da vila à cidade com o nome de Oeiras, e a mudança do nome da capitania para São José do Piauí, em homenagem ao monarca português. Em carta de 16 de fevereiro de 1762, noticiou a primeira resolução a Mendonça Furtado, protestando toda a deferência aos seus protetores (o próprio secretário da Marinha e seu irmão, então conde de Oeiras). Justificava a escolha do novo nome da capital nos seguintes termos: "porque dele inferirão não só os atuais moradores da mesma vila como ainda os vindores [sic], que os senhores da verdadeira Oeiras foram o instrumento da felicidade deste país". ${ }^{28}$

O esforço de João Pereira Caldas para estruturar o Piauí cimentou-lhe o caminho para novas promoções no Real Serviço. Em um mapa dos governadores que atuaram no Estado do Maranhão, desde a sua criação até o ano de 1783, num campo denominado "apêndices em serviços e ações", o mencionado feito foi assinalado como o mais significativo da trajetória de João Pereira Caldas. ${ }^{29}$

\section{De volta ao Reino: acerto de casamento e nova comissão}

Não há muitas informações sobre o período compreendido entre a volta de João Pereira Caldas a Portugal, em 1769, depois de concluir o governo do Piauí, e sua posse como capitão-general do Estado do Grão-Pará e Rio Negro, três anos depois. De acordo com o naturalista Alexandre Rodrigues Ferreira, antes de deixar a vila de Oeiras em direção ao Maranhão a fim de embarcar para Lisboa, Pereira Caldas teria sofrido uma espécie de obstrução intestinal, devidamente tratada com vinho emético e sanada quando da chegada a São Luís. Posteriormente, no Reino, teria sido acometido de bexigas. ${ }^{30}$

27 IHGB. Lata 358, doc.25

28 IANTT. Ministério do Reino. Maranhão, maço 601

29 Lisboa. Biblioteca da Ajuda (BA). 54-XI-27, n.17. Relação por mapa, dos governadores capitães-generais e dos capitães-mores que governaram o Maranhão e Pará; e depois esta última distinta e separadamente até 1783, fl.25.

30 FERREIRA, Alexandre Rodrigues. Diário da viagem filosófica pela capitania de São José do Rio Negro com a informação do estudo presente. Revista do Instituto Histórico e Geográfico Brasileiro, Rio de Janeiro, t.51, n.1, 
O mau estado de saúde pode não ter sido a razão mais importante para o retorno de Pereira Caldas à Corte. Assuntos familiares pendentes demandavam a sua presença. Depois da morte do brigadeiro Gonçalo Pereira, em 1761, os negócios de sua Casa - prejudicados pela longa permanência no ultramar - se desorganizaram. Cabia ao primogênito socorrer a mãe e resolver os eventuais apuros financeiros. Nem todas as questões chegaram a termo no período que precedeu a volta de Pereira Caldas ao Grão-Pará. Somente em 1774, dois anos depois de tomar posse, um decreto régio deuIhe autorização para vender nove prazos na vila de Monção, sete aforados ao Mosteiro de São João de Longos Vales, um ao Mosteiro de São Fins e outro ao Colégio de S. Paulo. A mercê foi concedida em atenção ao fato de o requerente encontrar-se "há mais de 20 anos ausente da dita sua Casa e ocupado no Real Serviço". Não obstante as dificuldades financeiras que obrigaram João Pereira Caldas a se desfazer de propriedades da família, recebeu o título do Conselho de Sua Majestade e teve satisfeita uma antiga mercê: o usufruto da metade de uma tença de 100 mil réis (assentada na Alfândega do Porto) concedida ao seu avô, que renunciou à mesma em favor dos filhos Antônio Pereira de Castro Caldas e Gonçalo Pereira Lobato e Sousa. Este, por sua vez, também renunciou à mercê em favor dos filhos João e Gonçalo José Pereira Caldas. ${ }^{31}$

Outro assunto que ocupou o militar no Reino foi o casamento com a "prima", D. Maria Engrácia de Almada e Mendonça, ajustado por volta de 1766. Aprovado pela mãe do noivo, D. Joana Maria Pereira de Castro, o consórcio não havia se confirmado porque carecia do assentimento de Francisco Xavier de Mendonça Furtado, justificado por Pereira Caldas nos seguintes termos:

Depois que V.Ex. a por um natural efeito da sua grandeza e benevolência se dignou tomar-me debaixo da sai alta proteção, favorecendo e acreditando a minha humildade com tantos, tão repetidos, e tão distintos benefícios, foi sempre a minha determinação a de não dispor e tratar o meu casamento sem inteiramente o fazer dependente da vontade e aprovação de V.Ex. ${ }^{a}$.

O consentimento de Mendonça Furtado permitiria que D. Maria Engrácia fosse formalmente pedida em casamento e que $D$. Joana Maria recebesse as procurações do filho para ultimar o consórcio. Este reforçava a aliança entre o secretário de Estado e João Pereira Caldas, unidos por um "amor de pai" e pela gratidão "dos grandes e repetidos sacrifícios com que tem tão penhorada a minha obrigação". ${ }^{32}$

vol.76, p.154-156, 1888

31 IANTT. Ministério do Reino. Decretos (1745-1800). Pasta 22, n.54; Registro Geral de Mercês. D. José I, livro 23 fls. 270 e 336.

32 AHU. Manuscritos Avulsos do Piauí (MAPI). CD 2, cx.9, doc.558. 
O casamento aproximaria João Pereira Caldas de uma família da nobreza senhorial, da região do Porto, engrandecida por serviços prestados à monarquia. D. Maria Engrácia era filha de Francisco de Almada e Mendonça, 1 o visconde de Vila Nova de Souto de El-Rei, e sobrinha de João Manuel de Almada e Melo, tenente-general dos Exércitos Reais. Eram primos de Sebastião José de Carvalho e Melo e de Francisco de Mendonça Furtado, o que explica o fato de os Almada terem sido tratados por "tios" em uma carta de João Pereira Caldas à mãe, em resposta a uma missiva em que a mesma comunicou-lhe o ajuste do casamento, "mais conseguido ao efeito da distinta honra com que me favorecem meus tios (...) João e Francisco de Almada (...) do que do meu merecimento". Assim, por meio do matrimônio, Pereira Caldas reforçaria seus vínculos com o círculo de aliados de Sebastião José de Carvalho e Melo. João e Francisco de Almada eram filhos de Antônio José de Almada e Melo, alcaide-mor de Palmela, senhor de diversos morgados, dentre os quais o dos Olivais e de Souto de El- Rei, e cavaleiro da Ordem de Santiago da Espada. O primogênito, João, herdou os senhorios da família e se casou com D. Ana Joaquina de Lencastre, sobrinha do $1^{\circ}$ conde da Lousã, nomeado vice-rei da Índia em 1765. À época do acerto do enlace de Pereira Caldas com D. Maria Engrácia, Almada e Melo exercia o governo das Armas e da Relação do Porto, tendo nele permanecido mais de 20 anos (1764-1786). ${ }^{33}$

Francisco de Almada e Mendonça despontou no Real Serviço ao ser nomeado ministro plenipotenciário em Roma (1768) com a missão de promover o restabelecimento das relações diplomáticas entre Portugal e a Santa Sé, rompidas desde 1760, e acabar de vez com as pretensões da Companhia de Jesus de retornar aos territórios lusitanos. O papa Clemente XIV (1769-1774) comprometeu-se com as instâncias de Portugal, da França e da Espanha, de onde os jesuítas tinham sido expulsos, e por meio de um Breve de 1773 declarou extinta a Ordem. Bem-sucedido no cumprimento do duplo encargo, Francisco de Almada e Mendonça foi premiado com o título de visconde de Vila Nova de Souto de El-Rei por decreto de 17 de maio de $1774 .{ }^{34}$

Contudo, imprecisões acerca de alguns dados biográficos do visconde e, por conseguinte, de sua filha, lançaram dúvidas sobre a concretização do seu casamento com João Pereira Caldas. Segundo Felgueiras Gayo e o autor d'A descendência portuguesa de D. João III, o visconde de Vila Nova de Souto de El-Rei era pai de D. Maria Engrácia e de José de Almada, mas ambos silenciaram sobre a existência de uma esposa e mãe dos mesmos

33 Cf. MONTEIRO, Nuno Gonçalo. O governo da monarquia e do Império, p.514. Ver também MONTEIRO, Nuno Gonçalo. O crepúsculo dos grandes. A Casa e o patrimônio da aristocracia em Portugal (1750-1832). $2^{\mathrm{a}}$.ed. Lisboa: Imprensa Nacional/Casa da Moeda, 2003, p.118 e 535-536.

34 Cf. ZÜQUETE, Afonso Eduardo Martins. Nobreza de Portugal e do Brasil. $3^{a}$.ed. Lisboa: Edições Zairol, 2000, v. 3, p.516. 
rebentos. Enquanto isso, outro genealogista registrou que Francisco de Almada e Mendonça faleceu sem geração. ${ }^{35}$ Teria dito, indiretamente, que o visconde não teve descendência legítima ou que morreu solteiro?

As dúvidas só aumentaram quando no lugar do nome do marido de $\mathrm{D}$. Maria Engrácia, em vez de João Pereira Caldas apareceu o de certo Gonçalo da Silva Alcoforado Rebelo e Lencastre - talvez aparentado da Casa da Lousã - com quem D. Maria teria se casado no Porto, em 7 de maio de 1769, cerca de três meses antes de Pereira Caldas encerrar o governo do Piauí (em 3 de agosto). ${ }^{36}$ Nesse caso, D. Maria Engrácia teria contraído núpcias dentro do mesmo círculo familiar de seu tio, João de Almada e Melo. Um elemento que favorece a idéia do casamento nesse círculo é o segundo casamento de Gonçalo da Silva Alcoforado. Viúvo de D. Maria Engrácia, contraiu núpcias com uma prima em segundo grau da falecida esposa, D. Guiomar Josefa de Almada e Melo, neta de João Manuel de Almada e Melo. ${ }^{37}$ Por outro lado, o silêncio de João Pereira Caldas sobre a tão almejada aprovação do consórcio por Francisco Xavier de Mendonça Furtado e a ausência de notícias sobre sua realização fortalecem a suspeita de que a união acordada não se concretizou. Restou ao militar aceitar uma nova comissão na mesma jurisdição em que já havia atuado.

\section{A recuperação econômica do Estado do Grão-Pará e Rio Negro}

Um discurso de autor desconhecido, proferido na posse de João Pereira Caldas, em 21 de novembro de 1772, realçava logo no início a "felicidade" com que os paraenses receberam a notícia da vinda do novo governador, cuja "veloz fama e a própria experiência Ihe tem feito adquirir das heróicas e imortais virtudes". ${ }^{38}$ Estas, e não os feitos de seus antepassados, o tornaram grande. Enviado pela "providência" que escolheu o Grão-Pará para "teatro" de suas "heróicas ações" - prosseguia o discurso - iniciara a carreira naquelas terras como capitão de Infantaria, depois ajudante de ordens do general do Estado e integrante da expedição que foi ao Rio Negro demarcar os limites previstos no Tratado de Madri. A vivência construída na Amazônia não escapou ao orador: "quem o diria (...) que vindo V.Ex. ${ }^{a}$ a governar este Estado, os conhecimentos adquiridos pela própria experiência o haviam de habilitar para o melhor exercício do mesmo governo".

35 GAYO, Felgueiras. Nobiliário das famílias de Portugal. 2a .ed. Braga: Edições Carvalhos de Basto, 1989, v. I, p.226 e v. V, p.170. CANEDO, Fernando de Castro da Silva. A descendência portuguesa de D. João III. 2ª .ed. Braga: Edições de Carvalhos de Basto, 1993, v.l, p.467.

36 Cf. CANEDO, Fernando de Castro da Silva. A descendência portuguesa de D. João III, v.l, p.467.

37 Cf. ZÜQUETE, Afonso Eduardo Martins. Nobreza de Portugal e do Brasil, v.3, p.516.

38 FBN. DM. Coleção Alexandre Rodrigues Ferreira. 21, 1, 044, n.001. 
As transformações político-administrativas do momento também se apresentaram no discurso, entrelaçadas à trajetória de João Pereira Caldas:

A grande vastidão da capitania do Maranhão (...) fazia menos salutíferos [sic] os influxos d' um bom governo (...). Criou-se uma nova capitania para remediar este mal. E foi V.Ex. ${ }^{a}$ eleito para moderador desta criação (...). A conhecida dificuldade desta empresa mostra bem qual era o grande conceito que o monarca fazia dos talentos de V.Ex. ${ }^{a}$.

O autor do discurso expôs as razões de a escolha do rei ter recaído em Pereira Caldas:

Em um governo já estabelecido correm os negócios um [certo] giro, de que ordinariamente não saem, porém na criação de um novo governo é necessário estabelecer a ordem das cousas, dirigi-las a seus fins, aplicar as leis e os negócios, que mil circunstâncias fazem diversos. O clima, a natureza do terreno, a diferença das suas produções, a qualidade dos habitadores [sic], os seus costumes, os países confrontantes: Para estabelecer a harmonia entre estes diferentes objetos, precisa-se uma não vulgar atenção, um discernimento pronto e judicioso. O vigilante cuidado com que V.Ex. ${ }^{a}$ se houve na criação do governo do Piauí é conhecido no fruto desta vigilância.

Em suma, esperava-se que o novo governador - consagrado pela estruturação do Piauí - edificasse uma "famosa época na história do Pará".

Essa fase que se pretendia fosse inaugurada por João Pereira Caldas coincidia com a divisão do Estado, da qual resultou o Estado do Grão-Pará e Rio Negro. As instruções recebidas na Corte estabeleciam que as diretrizes implantadas por Mendonça Furtado em 1751 deviam ser obedecidas à risca, pois, diante dos efeitos observados pela metrópole, "a melhor instrução que se pode dar à V.Ex. ${ }^{a}$ é a de lhe recomendar a execução das mesmas ordens, e de prosseguir tudo o que elas prescrevem com o maior cuidado", especialmente no que se referia à "civilização e liberdade dos índios" e ao aumento do comércio com áreas limítrofes, como Mato Grosso. ${ }^{39}$

Os meios para promover o crescimento do Grão-Pará estavam relacionados ao incentivo dos moradores às culturas do arroz e do anil, destinadas à exportação. Decorrido menos de um mês da posse, João Pereira Caldas mandou publicar um edital conclamando os colonos e os diretores das povoações a aplicar os índios sob sua jurisdição nos trabalhos agrícolas. Contudo, as morosas obras da vila de São José de Macapá, em que se empregavam muitos nativos, constituíam obstáculos ao emprego dos mesmos na lavoura. Muitos fugiam para os matos "desgostosos e oprimidos

39 FBN. DM. 19, 4, 2, doc.496, fls.264v-269v. 
de tanto trabalho" e, com isso, perpetuava-se um círculo vicioso, pois além de faltar braços para as obras públicas, escasseava a mão-de-obra a ser distribuída entre os moradores para a extração das drogas do sertão. As dificuldades de ordem financeira, verificadas nos governos anteriores, não tardaram a aparecer, levando à impossibilidade de satisfazer os pagamentos das folhas eclesiástica, civil e militar e aos cortes de despesas tidas por supérfluas. ${ }^{40}$

Mais interessante do que discorrer sobre a aplicação das instruções formais é tratar de um projeto que, longe de ser desconhecido dos historiadores, visava à ampliação do circuito comercial do Estado, partindo de Belém. Pouco antes de partir de Lisboa, Pereira Caldas teria se reunido em casa de Sebastião José de Carvalho e Melo, já elevado a marquês de Pombal, à Rua Formosa, juntamente com os secretários Martinho de Melo e Castro e José de Seabra da Silva, e quatro deputados da Companhia de Comércio do Grão-Pará e Maranhão. O encontro teria resultado na elaboração das "instruções secretíssimas" para a recuperação econômica do Estado do Grão-Pará, a partir de contatos comerciais com as possessões castelhanas das regiões de Quito, do Peru e do Orinoco. ${ }^{41}$

Corcino Medeiros dos Santos apontou que a busca da prata era o móvel principal do esquema, uma vez que a principal via de acesso às regiões produtoras da América espanhola (o Rio da Prata) estava comprometida, pois a Colônia do Sacramento caíra em mãos castelhanas. Para o historiador, o plano de comércio sistematizava um projeto acalentado pelo marquês de Pombal pelo menos desde 1770. Visava à introdução de mercadorias nos domínios de Espanha, por intermédio da Companhia de Comércio, permitindo em contrapartida o afluxo do metal precioso. ${ }^{42}$

Ângela Domingues ressalta que um plano de comércio com territórios castelhanos foi concebido anos antes por Manuel Bernardo de Melo e Castro (1759-1763), com a anuência de Francisco Xavier de Mendonça Furtado, para substituir os jesuítas no comércio clandestino na fronteira. O projeto consistia no estabelecimento de armazéns em pontos estratégicos, como o Rio Içá, e no seu abastecimento com mercadorias que pudessem interessar aos espanhóis radicados nas povoações próximas. Nesse sentido, as "instruções secretíssimas" de 1772 eram "a versão mais elaborada destes projetos de comércio ilegal com a Hispanoamérica". 43

Em trabalho mais recente, ao privilegiar a administração da capitania de Mato Grosso, Nauk Maria de Jesus reiterou os desígnios da Coroa portu-

40 IHGB. Seção do Conselho Ultramarino. Arq.1.1.3, fls.299v-300v e 305v-308

41 FBN. DM. Coleção Linhares. I-29, 18, doc. 6625, n.5.

42 SANTOS, Corcino Medeiros dos. A prata espanhola e o secretíssimo plano de comércio. Anais da XVI Reunião Anual da SBPH. Curitiba, 1997, p.163-167.

43 DOMINGUES, Ângela. Quando os índios eram vassalos. Colonização e relações de poder no norte do Brasil na segunda metade do século XVIII. Lisboa: Comissão Nacional para as Comemorações dos Descobrimentos Portugueses, 2000, p.228-229. 
guesa ao colocar em prática o plano de comércio, ressaltando que devido às "disputas em torno da Colônia do Sacramento as autoridades lusas se voltaram para as fronteiras Norte e Oeste". Isso explica o estreitamento dos contatos com Orinoco, Quito e Peru - fora dos domínios portugueses -, e com Vila Bela da Santíssima Trindade, capital de Mato Grosso. ${ }^{44}$ A ampliação do raio de ação da Companhia de Comércio foi justificada do seguinte modo:

Constituem estes [negócios] no grosso e fecundo comércio que a Companhia Geral (...) pode facilmente dilatar pela capitania do Mato Grosso e Cuiabá a outras do Brasil e pode introduzir na maior parte das vastas províncias espanholas (...) com grande vantagem ao que antes se fazia pela Colônia do Sacramento, sem que os respectivos governadores confinantes o possam facilmente impedir. ${ }^{45}$

Para tanto, João Pereira Caldas, encarregado da direção geral dos trabalhos, deveria estabelecer, com recursos da Companhia de Comércio, sete feitorias em lugares estratégicos, desde Belém, passando pelas vilas de Barcelos, de São José do Javari e de Borba, no Rio Negro, até Vila Bela, em Mato Grosso. O governador desta capitania, Luís de Albuquerque de Melo Pereira e Cáceres, foi devidamente comunicado do plano e ficou à espera de instruções ${ }^{46}$ Pelos rios da bacia amazônica, o fluxo das mercadorias, cujos preços seriam regulados pela Companhia, tornar-se-ia mais ágil.

As "instruções secretíssimas" referiam-se com mais detalhe ao comércio com Mato Grosso. Dessa forma, além de informações sobre o estabelecimento das feitorias, o diretor geral do plano receberia uma "relação dos exorbitantes preços" dos escravos africanos e dos gêneros secos e molhados vendidos naquela capitania. Conheceria também a "cruel indigência em que aquelas terras se acham dos remédios necessários para a cura dos enfermos", tudo isso graças às longas jornadas a partir do Rio de Janeiro (dois anos) e da Bahia (um ano e meio). As feitorias atalhariam a comunicação entre Belém e Vila Bela e, com isso, a "capital do Grão-Pará há de absorver todo o comércio do Mato Grosso, do Cuiabá e das extremidades das mais capitanias confinantes". O centro irradiador de todo o comércio da região amazônica - Belém - ligar-se-ia também às "outras capitanias dos domínios de Espanha que estão recebendo os (...) gêneros por trajetos e caminhos de terra tão remotos, e ainda mais árduos do que são os da Bahia e Rio de Janeiro". ${ }^{47}$

A comunicação com Mato Grosso era um projeto bem mais antigo. Em carta de 27 de junho de 1751, D. Antônio Rolim de Moura, então go-

\footnotetext{
44 JESUS, Nauk Maria de. Na trama dos conflitos. A administração na fronteira oeste da América portuguesa. Niterói: UFF, 2006, p.375 (História, Tese de doutorado).

45 FBN. DM. Coleção Linhares. I-29, 18, 25, doc.66, n.5.

46 Rio de Janeiro. Arquivo Nacional. Fundo: Secretaria de Governo da Capitania do Pará. Códice 100, fl.1.

47 FBN. DM. Coleção Linhares. I-29, 18, 25, doc. 66, n.5.
} 
vernador de Mato Grosso, expôs ao secretário Diogo de Mendonça Corte Real as "conveniências" de se franquear a comunicação entre Pará e Mato Grosso:

A primeira que do Pará hão de concorrer naturalmente muitas pessoas para aquelas minas. A segunda que as fazendas, e mantimentos do Reino vindos por ali hão de ser mais baratos, o que facilitará a subsistência dos seus moradores. A terceira que por aquela parte fica muito mais breve a comunicação com a Corte, donde pode ser socorrida esta capitania com grande brevidade. E quarta fazermo-nos senhores daquela navegação [do Rio Madeira]. ${ }^{48}$

No decorrer dos anos de 1773 e 1774, João Pereira Caldas deu seguimento às obras necessárias (construção de feitorias, fortificações) à execução do plano de comércio. Este contava também com um "eficaz sistema de corrupção das autoridades castelhanas" para ser viável. Tanto que, em junho de 1773, o governador de Mato Grosso, Melo e Cáceres, enviou a Pereira Caldas uma relação de peças que julgava próprias para subornar oficiais espanhóis e religiosos, dentre as quais havia "adereços de diamantes de bom gosto", "relógios de ouro com suas correspondentes chaves" e "seda de bom gosto e qualidade". ${ }^{49} \mathrm{Em} 8$ de março de 1773 (ou 1774), Pereira Caldas oficiou ao marquês de Pombal, comunicando-Ihe ter encarregado da construção da feitoria de São José do Javari o sargento-mor Diogo Luís de Barros e Vasconcelos, e que na mesma ocasião escrevera ao governador da província de Omáguas mandando o mesmo sargentomor "adiantar uma pequena carregação de fazendas para se apalpar e se ir principiando o negócio que principalmente por ali espero seja muito bem recebido". 50

Ao que parece, Diogo Luís de Barros e Vasconcelos teve sucesso na missão que lhe foi confiada. Segundo Corcino Medeiros dos Santos, o militar escreveu a Pereira Caldas informando ter chegado ao seu destino, via São Francisco Xavier de Tabatinga, e "que o governador espanhol ficou muito satisfeito e prometeu empenho no negócio". A partir da segunda metade de 1774, os primeiros resultados positivos começaram a ser colhidos. $O$ contrabando frutificava e a prata castelhana começava a afluir, afiançou Corcino Medeiros dos Santos. Entretanto, o historiador afirmou que o projeto caminhou "a passos lentos" e começou a declinar quando os representantes espanhóis nos governos das províncias de Santa Cruz de la Sierra, Mojos e Chiquitos foram substituídos, as Coroas ibéricas começaram a dar sinais de entendimento quanto à demarcação de limites - suspensa desde a anulação do primeiro Tratado de El Pardo (1761) e retomada com a assinatura

48 IHGB. Seção do Conselho Ultramarino. Arq.1.2.4, fls.3v-4

49 SANTOS, Corcino Medeiros dos. A prata espanhola e o secretíssimo plano de comércio, p.165.

50 IHGB. Seção do Conselho Ultramarino. Arq.1.1.3, fls.331v-333. 
do Tratado de Santo Ildefonso (1777) -, e o principal idealizador do plano de comércio, o marquês de Pombal, foi demitido. ${ }^{51}$

O projeto de expansão do comércio também rendeu dissabores a João Pereira Caldas, acusado de estar "envolvido em negócio para Mato Grosso e da Junta da Companhia do Comércio convidado de largas promessas de interesse para com as minhas informações a proteger a fim da sua continuação e existência". Segundo o governador, "as calúnias e os execrandos testemunhos" teriam surgido entre os "contrários partidistas e pretendentes da revogação e acabamento da mesma Companhia", extinta em 1778.

Para se defender das insinuações de que havia enriquecido com negócios escusos, Pereira Caldas reafirmou a honradez com que sempre servira à monarquia e mostrou-se consternado por causa de um "considerabilíssimo empenho e sem meios de o pagar [sic]". Suplicava à rainha, por intermédio de Martinho de Melo e Castro, que enviasse alguém para "conhecer e sindicar" a sua conduta e apurar a verdade. Desgostoso, rogava também a nomeação de um sucessor, confiante na "proteção" e no desejo de Melo e Castro de "querer amparar o meu crédito das calúnias contra ele inventadas", pois o mesmo podia julgá-lo "não só por conhecimento próprio, como pela informação das muitas pessoas que aí mesmo [em Lisboa] poderão abonar a minha conduta". ${ }^{52}$

João Pereira Caldas, ao que tudo indica, tinha boas e sólidas conexões na Corte, pois, mesmo diante dos rumores de improbidade e do ocaso de seus protetores - Francisco Xavier de Mendonça Furtado faleceu em 1769 e o marquês de Pombal foi demitido em 1777 -, não hesitou em reiterar antigas alianças. Meses antes de deixar o Grão-Pará, em 1780, escreveu a Sebastião José de Carvalho e Melo - desterrado e processado - para cumprimentá-lo e protestar reverência e gratidão pela proteção e pelos favores recebidos. Informou-lhe ainda ter passado o cargo a outra "criatura" do ex-secretário, José de Nápoles Telo de Meneses. ${ }^{53}$

\section{O valor da experiência: a questão de limites e a Viagem Filosó- fica}

Ao deixar Belém, Pereira Caldas não retornou para Portugal como esperava. Para a Coroa, era mais útil aproveitar a larga experiência adquirida pelo militar, exaltada no discurso proferido em sua posse no Grão-Pará, em 1772, e redirecioná-la para os trabalhos de demarcação do Tratado Preliminar de 1777, confirmado pelo de El Pardo (1778). Antes disso, porém, João Pereira Caldas entreviu nova possibilidade de deslocamento na

51 SANTOS, Corcino Medeiros dos. A prata espanhola e o secretíssimo plano de comércio, p.166.

52 IHGB. Seção do Conselho Ultramarino. Arq.1.1.3, fls.383v-384v e 386-387.

53 Lisboa. Biblioteca Nacional de Lisboa. Seção de Reservados. PBA 706, fls.15-15v. 
administração colonial: o governo de Mato Grosso. Seus "merecimentos e serviços" renderam-lhe a mercê de governar uma capitania "subordinada somente ao vice-rei e capitão-general de mar e terra do Estado do Brasil", segundo carta patente de 16 de dezembro de 1779. ${ }^{54}$ Mas a indicação não se efetivou.

Segundo as instruções de Martinho de Melo e Castro, depois de passar o cargo no Pará a José de Nápoles Telo de Meneses (1780-1783), Pereira Caldas deveria partir para uma fortaleza no Rio Negro ou para a sua capital, Barcelos, a fim de iniciar a tarefa de delimitação das fronteiras entre os domínios lusos e castelhanos, enquanto aguardava a chegada de Joaquim de Melo e Póvoas. Este, por sua vez, deixaria o governo do Maranhão para assumir o comando das demarcações e Pereira Caldas seguiria para Mato Grosso..$^{55}$ Porém, com a volta de Melo e Póvoas para Lisboa, o ex-governador do Grão-Pará se instalou em Barcelos como 1o comissário da 4 o divisão de limites.

Na mesma época iniciou-se a Viagem Filosófica (1783-1792) de Alexandre Rodrigues Ferreira pelas capitanias do Grão-Pará, do Rio Negro e de Mato Grosso, representativa do que Mauro Cezar Coelho classificou como um esforço da Coroa para superar as crises no Império ultramarino e buscar novas alternativas de exploração da natureza colonial. O naturalista baiano agia, portanto, como um "emissário político, um homem de Estado que vistoria e sugere solução aos problemas". ${ }^{56}$

Em recente trabalho sobre a atuação de viajantes e de naturalistas nos domínios portugueses, Ronald Raminelli destacou a importância da contribuição de governadores coloniais e demais agentes a serviço da Coroa, como João Pereira Caldas, para o bom andamento das expedições científicas. Por ter acumulado vasta experiência na região amazônica, Pereira Caldas foi de grande valia no fornecimento a Alexandre Rodrigues Ferreira de informações preciosas sobre população, agricultura, navegação e comércio locais. Prontificou-se a fornecer barcos, víveres e, conhecedor do Rio Negro, evitou que o viajante percorresse áreas povoadas de índios hostis, aconselhando mudanças de itinerário por terras mais seguras. Configurou-se, portanto, em um dos principais "patronos" da expedição científica, tendo ainda demonstrado em sua trajetória administrativa, segundo Raminelli, pendor para as ciências naturais. ${ }^{57}$ Uma faceta cuja análise excede os limites deste artigo, pois demanda um aprofundamento da

\footnotetext{
54 IANTT. Chancelaria de D. Maria I. Livro 15, fls.191v-192; Registro Geral de Mercês. D. Maria I, livro 8, fl.30.

55 FBN. DM. I-17, 12, 5, doc.6. Arquivo Histórico do Itamaraty. Documentação Rio Branco. Série Brasileira. Doc. 49 .

56 COELHO, Mauro Cezar. As viagens filosóficas de Charles-Marie de La Condamine e Alexandre Rodrigues Ferreira - ensaio comparativo. In: GOMES, Flávio dos Santos. (org.) Nas terras do Cabo Norte: fronteiras, colonização e escravidão na Guiana Brasileira, séculos XVIII/XIX. Belém: Ed. Universitária/UFPA, 1999, p.117-119.

57 RAMINELLI, Ronald. Viagens ultramarinas: monarcas, vassalos e governo à distância. São Paulo: Alameda, 2008, p.138-153.
} 
pesquisa em documentação específica, como as correspondências entre Alexandre Rodrigues Ferreira, Martinho de Melo e Castro, João Pereira Caldas e governadores da época.

A relação entre o comissário e o viajante, que tinham como elo na Corte o secretário Martinho de Melo e Castro, ficou patente em uma fala proferida pelo naturalista na celebração do natalício do comissário, em 1785, na vila de Barcelos. ${ }^{58}$ Ao comemorar 49 anos, Pereira Caldas recebeu uma homenagem em forma de panegírico que exaltava os feitos de seus familiares e as suas próprias virtudes. "No dia 4 de agosto de 1736 nasceu V.Ex. ${ }^{2}$, não para si, nem para os seus, mas para Deus, para o rei e para o Estado", começou o orador, emendando em seguida: "abriu V.Ex. a os seus olhos e registrando logo do berço as honradas paredes do (...) Solar de Sende, (...) os fitou nas penas e nas espadas com que defenderam e conservaram a pátria os seus gloriosos ascendentes". Idealizando a formação de Pereira Caldas, disse o panegirista: "se divertiu e escrever para descansar eram os ensaios da sua infância que, aliás, podia repousar sobre os serviços dos seus maiores".

Em seguida, foram realçados os préstimos da parentela do comissário quando o mesmo andava na casa dos 37 anos, privado da companhia paterna:

Já então se queixava o mais rico de todos os reis, de serem a seu ver tão insignificantes os prêmios que possuía para dignamente coroar os trabalhos do ilustríssimo senhor Gonçalo Pereira Lobato e Sousa, (...) brigadeiro dos seus exércitos e governador do Maranhão. Já então invejavam os grandes e animavam os pequenos os gloriosos exemplos de heroísmo (...) que liam nas ações do ilustríssimo senhor Bento Pereira de Castro, seu augusto tio, marechal dos exércitos e governador da praça de Valença.

Em seguida, o naturalista registrou algo intrigante:

Já então se prognosticava o soberano os vantajosos interesses que lhe resultaram da satisfação e acerto com que depois manejou bem delicados negócios (...) Francisco de Almada e Mendonça, visconde de Vila Nova [de Souto de El-Rei], embaixador que foi na Corte de Roma, em uma das situações mais críticas da soberania portuguesa. E já então era dívida em que estava a Coroa para com (...) João de Almada e Melo, o bastão de tenente-general dos exércitos (...) confiandoIhe para mais o honrar, o governo das Armas e o das Justiças do Porto.

Excetuando-se os parentes diretos e Francisco Xavier de Mendonça Furtado, não ficou evidente a razão da menção dos serviços dos irmãos Almada. Se o naturalista o fez por causa do suposto casamento de Pereira

58 IHGB. Lata 195, doc.7, n.3, fls.1-5. 
Caldas com a filha de Francisco de Almada, não contribuiu em nada para esclarecer a questão.

Desse ponto até o final do discurso, o orador fez uma espécie de epítome da carreira de João Pereira Caldas desde a chegada em Belém. Servira ao lado de Mendonça Furtado como capitão de Infantaria, sargento-mor e, mais tarde, na "curta idade de 21 anos" (equivocada, pois contava 22 para 23 em 1758-1759), coronel de Dragões, "não digo para governar, mas para criar um governo". Nesse sentido, o panegirista reafirmou que o momento fundador da carreira de João Pereira Caldas foi mesmo a indicação para o governo de São José do Piauí: "o prêmio da prudência, da equidade e da moderação com que V.Ex. ${ }^{a}$ governou o Piauí (...) foi o governo do Pará (...); o galardão deste encargo foi o (...) da demarcação a que V.Ex. ${ }^{a}$ preside". Em suma, "o Piauí foi domado, o Pará policiado e a demarcação empreendida". Neste aspecto, Alexandre Rodrigues Ferreira cedeu aos apelos do encômio em detrimento da realidade dos fatos, pois as divergências entre as comissões lusa e castelhana retardaram a satisfação das questões de limites previstas no Tratado de Santo Ildefonso.

De qualquer modo, o ano de 1785 foi de homenagens a João Pereira Caldas. O comandante militar da vila de Ega, no Rio Negro, Henrique João Wilkens, dedicou-lhe um poema heróico - Muhuraida ou o triunfo da fé... - composto em seis cantos. Na introdução crítica à obra, David H. Treece destacou que diferentemente de outros poemas históricos da segunda metade do século XVIII, como O Uraguai (1768) e Caramuru (1781), muito mais centrados no drama dos personagens, Muhuraida enfatizava o contexto político e a realização de medidas voltadas para as populações indígenas, apontando limites e contradições. ${ }^{59}$

Os Muras eram um problema a ser contornado. Ângela Domingues ressaltou que os constantes ataques dos numerosos índios aos colonos luso-brasileiros, mal armados e desprotegidos, em finais da década de 1750, alastraram-se do rio Madeira para outras povoações recém-fundadas, como Silves, Ega, Poiares e Airão. Com isso, ameaçavam o estabelecimento de novos núcleos populacionais e comprometiam as comunicações do GrãoPará com Mato Grosso por meio da "livre navegação do eixo fluvial Madeira - Mamoré - Guaporé". ${ }^{60}$ Disseminando o medo de roçar e de pescar nos moradores do Rio Negro, os Muras punham em risco o abastecimento da capitania, conforme anotou o ouvidor Francisco Xavier Ribeiro de Sampaio, após uma visita de correição pelo Rio Negro entre 1774 e $1775 .{ }^{61}$

59 WILKENS, Henrique João. Muhuraida ou o triunfo da fé na bem fundada esperança da inteira conversão e reconciliação da grande e feroz nação do gentio Muhura. Introdução crítica de David H. Treece. Manaus: Biblioteca Nacional/UFAM/Governo do Estado do Amazonas, 1993, p.16-17.

60 DOMINGUES, Ângela. Quando os índios eram vassalos, p.284-285.

61 SAMPAIO, Francisco Xavier Ribeiro de. Diário da viagem que em visita, e correição das povoações da capitania de São José do Rio Negro fez o ouvidor, e intendente geral da mesma... nos anos de 1774 e 1775. Lisboa: Tipografia da Academia Real das Ciências, 1825, p.22-23. 
Depois de sucessivas guerras e perseguições, os Muras foram aldeados a partir de 1784, tendo manifestado esse desejo e escolhido o melhor lugar para tal. O autor da Muhuraida, aspirante à proteção de João Pereira Caldas, creditou o sucesso da empresa ao comissário de limites, conforme os seguintes versos do canto quarto:

Este o tempo feliz, que destinava,

O céu para que em vós a luz raiasse;

Que aquele, que este Estado governava

Perto de vós, enfim, também se achasse

O ilustre João Pereira, que buscava,

Os meios que ninguém vos molestasse;

Fé tendo, incontrastável esperança,

Que Deus em vós faria esta mudança. ${ }^{62}$

O poema cantava as glórias da colonização e de um de seus agentes, mas é preciso notar, assim como o fez Ângela Domingues, certo protagonismo dos Muras no desfecho das hostilidades. Além disso, advertiu David Treece, a pacificação daqueles índios não derivou das fervorosas preces de D. Frei Caetano Brandão, bispo do Pará (1783-1789), - o que explica o "triunfo da fé" expresso no subtítulo da Muhuraida - nem de uma agência divina que teve João Pereira Caldas por instrumento. Para Treece, o comissário viu na aproximação do gentio indômito a possibilidade de uma aliança. O que beneficiaria as demarcações e, em última instância, desentravaria a colonização do Rio Negro e de áreas próximas.

\section{Do Rio Negro ao Conselho Ultramarino - considerações finais}

Após ter se dedicado à demarcação dos territórios compreendidos entre a foz do rio Jauru e a do Japurá, João Pereira Caldas desligou-se da função de comissário de limites em 25 de novembro de 1788, sendo substituído por Manuel da Gama Lobo de Almada. Diz-se que por razões de saúde e por desentendimentos com o representante espanhol, Francisco de Requena. ${ }^{63}$ É certo que nos últimos tempos preocupava-se com os negócios de sua Casa, não resolvidos apesar da decisão de vender alguns prazos em 1770.

Entre os bens que administrava no termo de Valadares (comarca de Valença do Minho) havia o morgado de São Martinho de Alvaredo, ao qual estavam vinculadas as terras da Castanheira do Penso e os campos de Candão, além de uma quinta. Esta, por sua vez, compreendia algumas

62 WILKENS, Henrique João. Muhuraida ou o triunfo da fé, p.141.

63 Cf. SERRẪO, Joel. Caldas, João Pereira. Dicionário da história de Portugal e do Brasil. Porto: Iniciativas Literárias, 1971, v.2. 
propriedades livres de vínculo, que Pereira Caldas pretendia vender e "com o seu produto poder pagar as dívidas de seu pai". Como se vê, os 35 anos de serviço nas conquistas do Norte não debilitaram apenas a saúde do militar. Afetaram igualmente os bens de sua Casa. Partiu para o Reino quase um ano depois de se desligar da comissão de limites, em agosto de 1789. Meses mais tarde conquistou um lugar "ordinário de conselheiro de capa e espada no Conselho Ultramarino" - corolário de sua trajetória em recompensa pelos serviços prestados na América, sendo investido no cargo em 1 o de julho de $1790 .{ }^{64}$

Contudo, um exame das fontes relativas à instituição revelou a ausência de dados sobre a participação efetiva de João Pereira Caldas nas decisões e nos pareceres emitidos pelo Conselho. Restou apenas um aviso de José de Seabra da Silva, de 27 de março de 1794, sobre a concessão de uma licença de dois meses ao conselheiro, provavelmente por motivo de doença. ${ }^{65}$ Nesse sentido, a mercê da nomeação para o Conselho Ultramarino limitou-se ao reconhecimento da Coroa da experiência adquirida pelo militar na América portuguesa, que poderia ser útil na apreciação de consultas encaminhadas àquela instância metropolitana.

Falecido em 7 de outubro de 1794, aos 58 anos de idade, João Pereira Caldas dedicou mais da metade de sua vida ao Real Serviço. Com sua morte, o irmão mais novo, Gonçalo José Pereira de Castro e Caldas, marechal de campo e chefe do Regimento de Infantaria de Valença, tornou-se seu "universal herdeiro" - não há menção a viúva nem filhos. Na Corte, Gonçalo José demandou a satisfação dos despachos aos requerimentos feitos por João Pereira Caldas para ser remunerado por seus serviços, os de seu pai e dos "que lhe deixou seu tio, o marechal de campo Bento Pereira de Castro e Azevedo". Por tudo isso, recorria à graça régia a fim de livrar da "indigência a que se acha[va] quase reduzida" a sua família e "por meio da merecida remuneração de tantos serviços, prosseguir mais comodamente com tanto maior crédito no Real Serviço". ${ }^{6}$

Descontada a retórica peculiar a tais requerimentos compensatórios, é fato assinalável que a Casa de João Pereira Caldas pugnava contra dívidas desde a morte do Brigadeiro Gonçalo Pereira Lobato e Sousa. Contudo, é preciso ressaltar que, independentemente da especificidade de cada trajetória, o empobrecimento de uma família possuía duas faces. De um lado, arriscava-se o patrimônio. Era o ônus da participação no Real Serviço, que servia de argumento para alcançar a graça régia. De outro, salvaguardavase a honra, o prestígio da Casa e a sua sobrevivência em uma sociedade assentada nos valores do Antigo Regime.

64 IANTT. Chancelaria de D. Maria I. Livro 32, fl.358v; Registro Geral de Mercês. D. Maria I, livro 25, fl.205v.

65 AHU. Avulsos. Cx.10, doc. 919, microfilme n.10.

66 IANTT. Ministério do Reino. Decretos (1745-1800). Pasta 56, n.26. 